\title{
ФИНАНСОВЫЙ МЕХАНИЗМ МЕДИЦИНСКИХ ОРГАНИЗАЦИЙ В РФ
}

\author{
(c) 2018 Валиева Елизавета Николаевна \\ доктор экономических наук, профессор \\ Самарский государственный экономический университет \\ 443090, г. Самара, ул. Советской Армии, д. 141 \\ E-mail: rad8063@yandex.ru \\ (c) 2018 Курнакина Наталья Владимировна \\ кандидат экономических наук, заместитель главного врача по экономическим вопросам \\ Самарская стоматологическая поликлиника № 2 \\ 443009, г. Самара, ул. Свободы, д. 121 \\ E-mail: nv125@rambler.ru
}

Статья посвящена вопросам финансового управления в медицинских организациях. Представлен состав их финансового механизма. Дана характеристика его блоков и инструментов. Сформулированы предложения, направленные на развитие методов финансового менеджмента в здравоохранении.

Ключевые слова: медицинские организации, финансовый механизм в медицине.

В современных условиях финансовые отношения в экономике и социальной сфере формируются не произвольно - по мановению «невидимой руки» рынка А. Смита, а являются результатом регулирования для достижения стратегических и тактических целей государственной или корпоративной финансовой политики. Несмотря на реализацию ряда государственных программ, задача совершенствования организации и финансирования здравоохранения продолжает оставаться актуальной [4]. Организационно-экономические мероприятия и способы регулирования в области формирования и использования финансовых ресурсов в здравоохранении, разрабатываемые органами управления, образуют его финансовый механизм В широком смысле финансовый механизм - совокупность видов, форм организации финансовых отношений, специфических методов формирования и использования финансовых ресурсов и способов их количественного определения [6]. Конечными получателями финансовых ресурсов в здравоохранении являются медицинские организации. Наличие различных источников финансирования их деятельности предполагает использование системы инструментов и рычагов управления денежными потоками. «Каждому источнику финансирования соответствует специфический механизм использования: от предельной регламентации для бюджетного финансирования до самостоятель- ного распоряжения средствами, полученными от оказания платных медицинских услуг. В итоге, в составе медицинского учреждения оказывается нескольких субъектов хозяйствования с разными целями, механизмами финансирования и использования средств, полученных от их финансирования»,- считает Т.А. Бородина, рассматривая механизм согласования экономических интересов в здравоохранении [3].

На современном этапе финансовое планирование для медицинской организации заключается в формировании Плана финансово-хозяйственной деятельности. В основу положен принцип использования кадровых ресурсов и нормативной нагрузки. Медицинская организация определяет профиль врачей-специалистов, устанавливает нормативную нагрузку (функцию врачебной должности - количество услуг в год на 1 ставку врача). В результате суммирования получается объем услуг, который может оказать медицинская организация. Однако прикрепленное по системе ОМС население может нуждаться в медицинской помощи по такому профилю, специалист по которому в данном лечебно-профилактическом учреждении (ЛПУ) отсутствует. В этом случае медицинская организация направляет прикрепленного к ней застрахованного пациента в другое лечебно-профилактическое учреждение. В свою очередь, неприкрепленные к данной медицинской организации застрахованные лица могут получать услуги по направ- 
лениям из других ЛПУ. Такой же принцип используется при планировании стационарной и стационарозамещающей помощи. Как правило, практикуется процедура обоснования организацией плановых объемов медицинской помощи на следующий год в разрезе ее видов и профилей. Однако, ценовые и финансовые показатели рассчитываются только на уровне Комиссии по разработке программы. Для реализации возможности планирования медицинских услуг на уровне организации не предусмотрено единых методик. Планирование стоимостных составляющих на уровне медицинской организации может быть использовано только для оперативного расчета на период утверждения плановых объемов. Ценовые категории на год утверждаются Тарифным соглашением в прейскурантах на услуги по ОМС. Совокупная плановая сумма финансирования услуг определяется в плановом объеме, утвержденном Комиссией.

Качество составления предложений медицинской организации по оказанию услуг и его финансовому обеспечению играет очень важную роль. Сопоставление предложений медицинской организации с планом, утвержденным Комиссией по разработке программы [2], свидетельствует о том, насколько учреждение владеет ситуацией и способно ею управлять.

Планирование оказания платных услуг - самое слабое звено в управленческой деятельности медицинской организации. Оно сводится к составлению плана доходов и расходов при составлении Плана финансово-хозяйственной деятельности. Регламента для проведения таких мероприятий на уровне медицинских учреждений не существует. Фактически доходы от оказания платных услуг призваны «латать дыры» в финансовом обеспечении медицинской организации, вызванные ее хроническим недофинансированием из бюджетных средств и средств обязательного медицинского страхования. К этому выводу в своих работах приходят Ф.Н. Кадыров [5], С.М. Сюркова [6]. При внедрении научно-обоснованных методик планирования оказания платных услуг и их структуры, при грамотной тарифной политике медицинская организации имеет возможность значительно повысить эффективность своей финансовой деятельности.

В настоящее время финансирование расходов на оказание медицинской помощи в рамках государственного задания осуществляется без увязки с выполнением количественных показателей. Плановое задание содержит данные по количеству оказанных услуг. Затем определяется предельная сумма финансирования. Медицинская организация может превысить или не исполнить плановый показатель по объему предоставленной помощи, финансирование от этого не изменится. Установленный порядок мониторинга выполнения плановых объемов на ведомственном уровне [1] не используется лечебным учреждением для управления объемами помощи. Данный подход - остаточное явление сметного финансирования. Как таковая стоимость услуги и ее оплата по мере выполнения не предусмотрены. Нормативные затраты на единицу услуги служат для определения совокупного объема финансирования на год. При осуществлении расходов менеджмент ориентируется не на объемы оказанных услуг, а на план финансирования по кварталам внутри года.

В процессе финансово-хозяйственной деятельности создаются финансовые и денежные потоки, обеспечивающие формирование и получение доходов, осуществление расходов. Соответственно, финансовое управление медицинской организацией должно быть направлено как на регулирование процессов получения доходов (грамотное планирование, мониторинг выполнения планов, анализ, принятие управленческих решений), так и на контроль за расходованием финансовых средств. Контролируя соответствие фактических значений показателей плановым параметрам, медицинская организация способна управлять формированием доходной части своего ПФХД. Однако в целях финансового управления следует учитывать различия в периодах формирования фактических и кассовых доходов (табл. 1).

При планировании расходной части медицинская организация должна руководствоваться: объемом финансирования по каждому источнику, соответствием плана расходов и их структуры по определенному виду помощи нормативным показателям, обязательностью соблюдения натуральных норм расходов по определенным статьям, сроками осуществления кассовых расходов.

Для увязки оплаты расходных обязательств с финансовой возможностью организации в данном периоде, необходимо к каждой группе платежей применять определенные методы управления, которые изложены в табл. 2. Этот процесс 
Таблица 1. Сроки формирования фактических и кассовых доходов с учетом видов медицинской помощи и источников ее финансирования

\begin{tabular}{|c|c|c|}
\hline \multirow{2}{*}{ Вид помощи } & \multicolumn{2}{|c|}{ Сроки формирования доходов } \\
\hline & фактических & кассовых \\
\hline $\begin{array}{l}\text { Медицинские услуги в рамках ТП } \\
\text { ГГ за счет средств ОМС }\end{array}$ & $\begin{array}{l}\text { Выставление счетов за оказанные } \\
\text { услуги (1 раз в } 10 \text { дн) }\end{array}$ & $\begin{array}{l}\text { Авансовые платежи за текущий } \\
\text { месяц (40\% от среднемесячной } \\
\text { суммы) - с } 12 \text { по } 28 \text { число; расчет } \\
\text { за предыдущий месяц - с } 10 \text { по } 18 \\
\text { число }\end{array}$ \\
\hline $\begin{array}{l}\text { Медицинские услуги в рамках } \\
\text { выполнения государственного } \\
\text { задания за счет средств областного } \\
\text { бюджета }\end{array}$ & По итогам месяца & - \\
\hline $\begin{array}{l}\text { Оказание платных медицинских } \\
\text { услуг населению }\end{array}$ & $\begin{array}{l}\text { Выставление счетов за оказанные } \\
\text { услуги (ежедневно) }\end{array}$ & $\begin{array}{l}\text { Ежедневно или по мере заверше- } \\
\text { ния услуги }\end{array}$ \\
\hline $\begin{array}{l}\text { Оказание платных медицинских } \\
\text { услуг по договорам ДМС и с юри- } \\
\text { дическими лицами }\end{array}$ & $\begin{array}{l}\text { Выставление счетов за оказанные } \\
\text { услуги (1 раз в месяц) }\end{array}$ & В течение последующих 45 дн \\
\hline
\end{tabular}

Таблица 2. Методы управления, применяемые для организации процесса оплаты расходных обязательств медицинской организацией

\begin{tabular}{|c|c|}
\hline Группа платежей - кассовых расходов & Метод управления \\
\hline $\begin{array}{l}\text { Выплата заработной платы, отчислений во внебюд- } \\
\text { жетные фонды, уплата налогов }\end{array}$ & $\begin{array}{l}\text { Планирование фонда оплаты труда помесячно, кон- } \\
\text { троль за формированием ФОТ, управление фондом } \\
\text { стимулирующих выплат, организация оплаты труда } \\
\text { по показателям эффективности, организация про- } \\
\text { цесса начисления заработной платы }\end{array}$ \\
\hline $\begin{array}{l}\text { Ежемесячные платежи за содержание (оплата комму- } \\
\text { нальных услуг, другие ежемесячные платежи услов- } \\
\text { но-постоянного размера) }\end{array}$ & $\begin{array}{l}\text { Организация процесса заключения договоров, } \\
\text { контроля за объемом услуг, учета счетов за услуги, } \\
\text { помесячное планирование платежей }\end{array}$ \\
\hline $\begin{array}{l}\text { Оплата услуг, проводимых периодически (техниче- } \\
\text { ское обслуживание оборудования, производственный } \\
\text { лабораторный контроль, обучение сотрудников и } \\
\text { т.д.) }\end{array}$ & $\begin{array}{l}\text { Составление годового графика, отслеживание цен на } \\
\text { услуги в течение года, контроль за объемом услуг }\end{array}$ \\
\hline $\begin{array}{l}\text { Плата за разовые услуги (ремонт оборудования, авто- } \\
\text { транспорта) }\end{array}$ & $\begin{array}{l}\text { Создание резерва на незапланированные меропри- } \\
\text { ятия }\end{array}$ \\
\hline $\begin{array}{l}\text { Плата за приобретенные материальные ценности, в } \\
\text { основном за медикаменты }\end{array}$ & $\begin{array}{l}\text { Планирование расходов в рамках ПФХД по источни- } \\
\text { кам финансирования, работа комиссий по состав- } \\
\text { лению заявок на приобретение, организация дого- } \\
\text { ворного процесса, составление заявок на поставки, } \\
\text { управление сроками оплаты, графиками платежей }\end{array}$ \\
\hline
\end{tabular}

является основополагающим для обеспечения платежеспособности организации и затрагивает множество финансовых отношений (с работниками, налоговыми органами, поставщиками товаров и услуг).

Необходимо отметить, что сведения о кассовых расходах, относящихся к определенному виду медицинской помощи, не в полной мере фиксируются в учете, что допускает возможность некорректного отнесения расходов к тому или иному виду медицинской помощи. В отчетной информации о расходной составляющей при оказании определенного вида медицинской помощи могут быть допущены искажения.

В настоящее время отсутствует отчетность, отражающая итоги деятельности медицинской организации по оказанию услуг, по выполнению плановых объемов доходов и расходов, финансовому результату и показателям эффективности финансовой деятельности, а также результативности оказания медицинской помощи. Учитывая социальную значимость сферы здравоохранения и необходимость обеспечения безубыточности медицинских организаций, такой документ необходимо разработать и предусмотреть в составе отчетности. 
Финансовый механизм медицинской организации, используемый в настоящее время, можно представить в виде схемы (рисунок 1).

Таким образом, финансовому механизму медицинской организации в настоящее время свойственны следующие черты.

1. Стадия стратегического планирования на уровне ЛПу характеризуется низким качеством. Медицинская организация не планирует самостоятельно свою деятельность, исходя из принципов эффективности оказания услуг, в частности, по причине отсутствия информаци- онной базы.

2. Оперативное управление финансово-хозяйственной деятельностью медицинской организации характеризуется слабым контролем за соответствием производимых расходов доходам от оказанных услуг, что обусловливает финансовые риски в течение года.

3. Отсутствует блок управления безубыточностью, благодаря которому должны быть решены две задачи: обеспечение платежеспособности организации (в текущем периоде и стратегическом плане) и предоставление ин-

БЛОК 1 - Стратегическое планирование на 3-летний плановый период

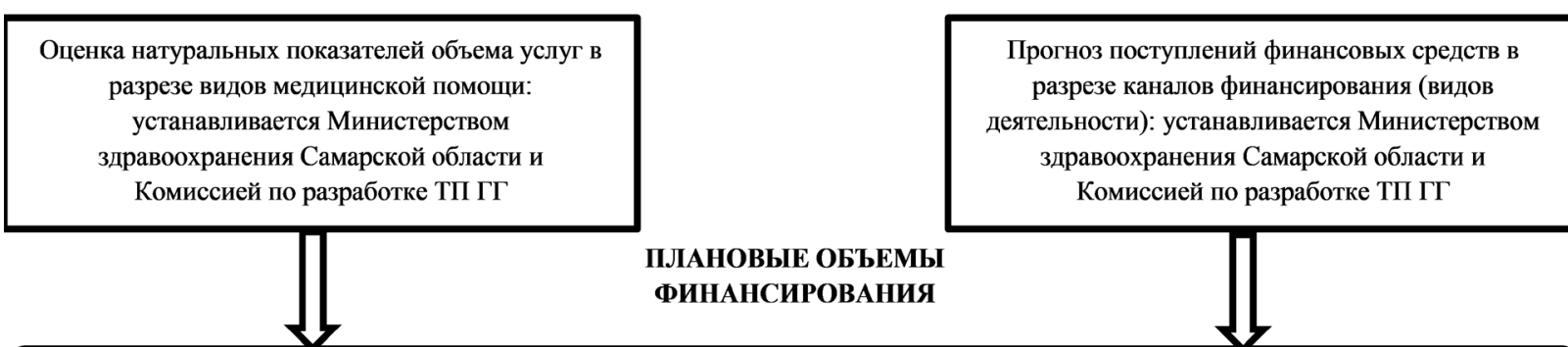

БЛОК 2 - Текущее планирование

Планы оказания медицинских услуг по видам помощи, подразделениям

ПФХД

ПЛАНОВЫЕ ЗНАЧЕНИЯ ПО

СТАТЬЯМ РАСХОДОВ
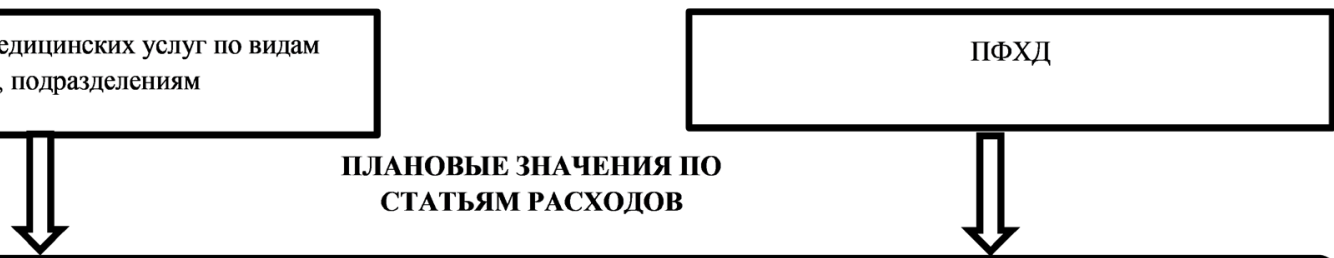

БЛОК 3 - Оперативное управление

Мониторинг выполнения планов оказания услуг по видам помощи, подразделениям

Исполнение ПФХД по доходам и расходам, внесение изменений в ПФХД
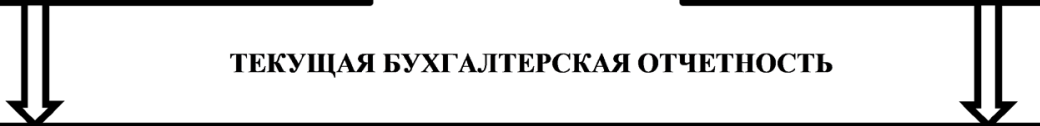

БЛОК 4 - Оценка эффективности и результативности оказания медицинской помощи

Сведения об оказании и ресурсном обеспечении медицинской помощи

Годовая бухгалтерская отчетность

Выполнение индикаторов государственной программы развития здравоохранения

Puc. 1. Состав финансового механизма медицинской организации 
формации для принятия управленческих решений по производственной деятельности. Расчет таких показателей, как рентабельность услуги, подразделения, вида помощи и медицинской организации в целом, позволит выявить ее проблемы, чтобы добиться эффективной работы.

4. Отсутствует система оценки эффек- безубыточности организации.

\section{Библиографический список}

1. О Порядке проведения мониторинга и контроля за выполнением государственного задания государственными бюджетными учреждениями Самарской области, подведомственными министерству здравоохранения Самарской области [Электронный ресурс]: приказ м-ва здравоохранения Самар. обл. от 10.02.2015 № 179.- - Режим доступа: http://minzdrav.samregion.ru/documents/prikazy/.

2. Объемы предоставления медицинской помощи и финансовых средств на обеспечение государственных гарантий оказания населению Самарской области бесплатной медицинской помощи за счет средств ОМС на 2016 год [Электронный ресурс]: протокол Комиссии по разработке ТП ОМС № 13-2016 от 20.12.2016.Режим доступа: http://samtfoms.ru/docs/.

3. Бородина Т.А. Механизм согласования экономических интересов в системе здравоохранения / Т.А. Бородина, Е.А. Колесниченко // Сб. науч. Тр. кафедры политической экономии и мирового глобального хозяйства. / отв. ред. М.А. Коломейцева. Тамбов. 2011. 97 с.

4. Валиева Е.Н. Модернизация финансового механизма обязательного медицинского страхования в РФ // Вестник Самарского государственного экономического университета. 2013. № 2. С. 17-22.

5. Кадыров Ф.Н. Платные услуги в здравоохранении / под ред. акад. РАМН В.И. Стародубова. Москва. 2013.220 c.

6. Курнакина Н.В. Финансовый механизм медицинских организаций в РФ // Вестник Самарского государственного экономического университета. 2014. № 11. С. 119-124.

7. Сюркова, С.М. Проблемы финансирования учреждений здравоохранения в период трансформации организационно-правовых и экономических условий их деятельности / С.М. Сюркова, Г.Г. Закирзянова // Вестник ТИСБИ. Томск, 2013. - № 2. С. 106-116. 